Article

\title{
Simultaneous Detection of 14 Microcystin Congeners from Tissue Samples Using UPLC- ESI-MS/MS and Two Different Deuterated Synthetic Microcystins as Internal Standards
}

\author{
Stefan Altaner ${ }^{1}$, Jonathan Puddick ${ }^{2} \odot$, Valerie Fessard ${ }^{3}$, Daniel Feurstein ${ }^{4}$, Ivan Zemskov ${ }^{5}$, \\ Valentin Wittmann ${ }^{5}$ and Daniel R. Dietrich $1, *$ (D) \\ 1 Human and Environmental Toxicology, University of Konstanz, 78457 Konstanz, Germany \\ Cawthron Institute, 7010 Nelson, New Zealand \\ 3 Toxicology of Contaminants Unit, French Agency for Food, Environmental and Occupational Health and \\ Safety, ANSES, 35306 Fougères, France \\ 4 Dr. Feurstein Medical Hemp GmbH, HANAFSAN, Hauptstr. 19A, 6840 Götzis, Austria \\ 5 Organic and Bioorganic Chemistry, University of Konstanz, 78457 Konstanz, Germany \\ * Correspondence: daniel.dietrich@uni-konstanz.de
}

Received: 5 June 2019; Accepted: 28 June 2019; Published: 2 July 2019

check for updates

\begin{abstract}
Cyanobacterial microcystins (MCs), potent serine/threonine-phosphatase inhibitors, pose an increasing threat to humans. Current detection methods are optimised for water matrices with only a few MC congeners simultaneously detected. However, as MC congeners are known to differ in their toxicity, methods are needed that simultaneously quantify the congeners present, thus allowing for summary hazard and risk assessment. Moreover, detection of MCs should be expanded to complex matrices, e.g., blood and tissue samples, to verify in situ MC concentrations, thus providing for improved exposure assessment and hazard interpretation. To achieve this, we applied two synthetic deuterated MC standards and optimised the tissue extraction protocol for the simultaneous detection of $14 \mathrm{MC}$ congeners in a single ultra performance liquid chromatography-tandem mass spectrometry (UPLC-MS/MS) run. This procedure was validated using plasma and liver homogenates of mice (male and female) spiked with deuterated MC standards. For proof of concept, tissue and plasma samples from mice i.p. injected with MC-LR and MC-LF were analysed. While MC-LF was detected in all tissue samples of both sexes, detection of MC-LR was restricted to liver samples of male mice, suggesting different toxicokinetics in males, e.g., transport, conjugation or protein binding. Thus, deconjugation/-proteinisation steps should be employed to improve detection of bound MC.
\end{abstract}

Keywords: cyanobacterial toxin; deuterated MC standards; microcystin; blood; liver tissue; UPLC-MS/MS; quantification

Key Contribution: The use of deuterated microcystin standards and an improved extraction procedure using UPLC-MS/MS analytics, provides for the simultaneous detection of fourteen microcystin congeners. Thus, it allows more accurate quantitation of total microcystin load of a given sample in complex matrices like blood or tissue, and therefore better hazard interpretation.

\section{Introduction}

In recent years, reports of cyanobacterial blooms have increased [1]. Water bodies experiencing cyanobacterial bloom formation often additionally contain toxins, like microcystins (MCs), which can pose a serious health threat to humans. This was demonstrated in Caruaru in 1996, when 76 patients 
died because of the use of contaminated water for hemodialysis [2]. MCs are cyclic heptapeptides, comprised of rare and unique $\mathrm{L}$ - and $\mathrm{D}$-amino acids and two variable $\mathrm{L}$-amino acid positions ( $\mathrm{X}$ and $Z$, Figure 1), which are also used for nomenclature, e.g., MC-LR has L-leucine in the $X$ position and $\mathrm{L}$-arginine in the $\mathrm{Z}$ position. Along with the variable amino acids, methylations and demethylations at other positions have led to more than 200 congeners being identified to date [3].

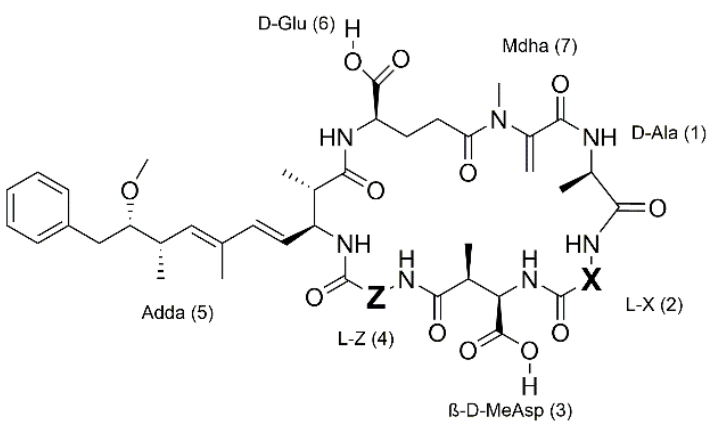

Figure 1. General structure of microcystins where $X$ and $Z$ are variable L-amino acid positions. $\beta$-D-MeAsp is erythro- $\beta$-D-methylaspartate; Mdha, $\mathrm{N}$-methyldehydroalanine, Adda, $(2 \mathrm{~S}, 3 \mathrm{~S}, 8 \mathrm{~S}, 9 \mathrm{~S}, 4 \mathrm{E}, 6 \mathrm{E})$ 3-amino-9-methoxy-2,6,8-trimethyl-10-phenyl-4,6-decadienoic acid.

Differential transport of MC congeners by organic anion transporting polypeptides (OATPs) has been shown to result in different cell and tissue loads [4,5]. Additionally, export of MC is still under research, although recent data suggest export of MC by MRP2 in an MC congener-dependent fashion as observed earlier for OATPs [6,7]. As the liver displays high expression of OATPs and MC exposure mainly occurs via the oral route, the liver is generally accepted to be the main target organ. In the target cells, MC is either freely available (unbound) or covalently bound to serine/threonine-protein phosphatases (PPPs), conjugated to glutathione [8] or other cysteine-containing polypeptides and proteins. The irreversible inhibition of PPPs by MCs, and consequently the downstream protein-hyperphosphorylation, is currently assumed to be the predominant mechanism underlying MC cytotoxicity. Most members of the PPP-family are known to be affected by MCs [9], albeit with different susceptibilities [10]. Indeed, structural features of MC congeners appear to have a major impact on the "tightness" of MC binding to the catalytic subunit of PPP [11,12], thus resulting in the observed differing PPP inhibition capacities. Thus, information as to whether a specific MC congener was involved in a given toxicity observed, and at what tissue concentration adverse effects manifest, is crucial for a better understanding of MC congener differences in exerting overt toxicities and consequently for better delineating risk for human health.

MC detection is generally carried out via ELISA or chromatographic methods coupled to mass-spectrometric analysis (LC-MS) [13,14]. ELISA methods may differ in the antibodies used, and thus their capability to detect the majority of MC congeners present in a given sample. Indeed, while antibodies raised against the arginine epitope in MC-LR primarily recognise arginine containing MC congeners [15], antibodies raised against Adda potentially recognise $85 \%$ of the known congeners [16]. Similarly, the MS-based MMPB method which detects the oxidation product MMPB (2-methyl-3-methoxy-4-phenylbutyric acid) of Adda [17,18], therefore showing similar coverage (86\%). As with the ELISA, only the sum of all MC and not specific MC congeners can be quantified. An advantage of the MS-based MMPB method, however, is that protein-bound MC can be detected as both bound-MC and free MC are oxidised [18], albeit whether bound-MC and free MC oxidation occurs with the same efficiency is currently under debate [19].

UPLC-MS/MS-based methods provide the possibility of simultaneous detection of different congeners in various sample types [20-25]. However, quantitation from complex matrices like blood or tissue homogenate is difficult due to matrix residues which may influence the signal (suppression or enhancement), thus leading to under- or over-estimation of the true amount of MC present. This could be alleviated with internal standards (ISs) that behave similarly to the MC congeners of interest analysed. 
Unfortunately, appropriate internal standards are still missing. Quantitation from various samples using ISs has been attempted previously $[20,26,27]$. However, in these approaches, either nodularin or thiolised MC-LR/-RR at the Mdha moiety was employed. Obviously all three ISs used in the latter approaches will differ in their behaviour during sample extraction, elution and analysis. In contrast, incorporation of stable isotopes is the best option for the generation of an IS. The latter ensures that during laboratory handling and analysis, a stable isotope-labelled compound has near-identical behaviour and is subject to the same matrix effects as the actual analyte in question.

Detection of analytes from tissue is often complicated due to the need for tissue extraction, and thus tissue specific matrix effects. Generally, extraction methods are optimised for a given sample type and for a single or a small number of $\mathrm{MC}$ congeners, primarily representing rather hydrophilic congeners, e.g., MC-RR, -LR and -YR. However, in view of the fact that several different MC congeners co-occur in a given cyanobacterial bloom [28,29], including the highly toxic MC-LF [30], the present work aimed to establish a quantitation method for a wider range of congeners in complex matrices allowing the analysis of congener specific organ distribution. Thus, deuterated internal standards ( $D_{7}-\mathrm{MC}-\mathrm{LR}$ and $\left.\mathrm{D}_{5}-\mathrm{MC}-\mathrm{LF}\right)$ were de novo synthesised, and present protocols for MC sample extraction were optimised and integrated into a UPLC-MS/MS-based analytical procedure. For proof of concept, tissue and plasma samples from MC-LR and -LF exposed mice were analysed.

\section{Results}

\subsection{Method Establishment and Optimisation}

MC-spiked serum samples were extracted using a previously published procedure for detection via ELISA [31] and subsequently analysed using a previously established UPLC-MS/MS method optimised for MC in cyanobacterial culture extracts [32]. The extraction method (Figure 2) consisted of three times protein precipitation (PP), followed by three times liquid-liquid partitioning (LLP) with n-hexane and subsequent solid-phase extraction (SPE). In the process, signal enhancement was observed for all MC congeners tested (data not shown), presumably due to carry-over of the previous sample as signal enhancement progressively increased with every additional injection. Therefore, a slower gradient with a prolonged washout phase (see Section 4.4) was used during UPLC, leading to stable detection of the MC congeners tested (comparable areas under the curve for multiple subsequent analyses of the same MC congener).

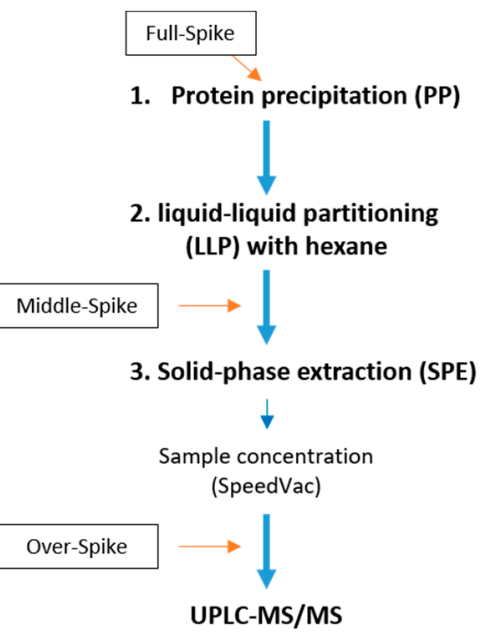

Figure 2. Scheme of the extraction highlighting different time points for spiking with MC congeners.

To determine whether and during which extraction steps potential loss of MC congeners would occur, MC spiking was introduced at different points of the extraction procedure (Figure 2) and the respective losses, i.e., recoveries of spiked MC, determined at each step using a backward approach, i.e., 
starting at the injection stage (Figure 2). Indeed, loss of signal was not expected at the injection stage into the UPLC-MS/MS (Over-Spike). Thus, the contribution of each phase of the extraction procedure to the loss of analyte was assessed by starting with the SPE columns and then working backwards to the PP.

Samples were spiked (Middle-Spike) with MC congeners prior to application to the SPE columns and the recoveries compared for three different SPE columns (Table 1 and Figure S1): Phenomenex StrataX (3 cc, $200 \mathrm{mg}$ sorbent), Waters Oasis HLB (6 cc, $200 \mathrm{mg}$ sorbent) and Waters Oasis PRiME HLB (6cc, $200 \mathrm{mg}$ sorbent). Although in a preliminary experiment, Supelco Hybrid-SPE Phospholipid and Phenomenex C18-E columns were also tested, these did not provide reliable data (data not shown), and therefore were not considered any further. The StrataX column presented overall recoveries ranging between 63.4 and $112.7 \%$, with the majority of congeners showing a recovery of 70\%. The PRiME HLB column showed acceptable recoveries (80.6-114.7\%) for congeners containing arginine residues (Table 1 and Figure S1), while a pronounced loss of non-arginated congeners was observed (recoveries: 57.9-78.3\%). In contrast, the HLB column presented better recovery for all MC congeners tested (72.6-108.7\%), with recoveries for the majority of congeners ranging between 85 and 100\%. A two-way ANOVA analysis of the latter data suggested that the recoveries determined were not significantly different from a control recovery of $100 \pm 10 \%$ obtained with MC congeners in $\mathrm{MeOH}$ solution (Over-Spike) applied to the UPLC-MS/MS without sample matrix and prior SPE column separation. Consequently, the HLB column was employed for all subsequent MC congener recovery and quantitation experiments.

Table 1. Congener dependent recovery during SPE and LLP steps of the extraction.

\begin{tabular}{ccccccccccc}
\hline & \multicolumn{4}{c}{ Solid Phase Extraction (SPE) } & \multicolumn{3}{c}{ Liquid-Liquid Partitioning (LLP) } \\
\hline & \multicolumn{3}{c}{ StrataX } & \multicolumn{2}{c}{ HLB } & PRiME HLB & \% in MeOH & \% in n-Hexane \\
\hline Mean & SD & Mean & SD & Mean & SD & Mean & SD & Mean & SD \\
\hline MC-RR & 63.4 & 2.3 & 90.4 & 6.0 & 100.9 & 5.8 & 89.0 & 9.9 & 0.6 & 0.0 \\
MC-YR & 112.7 & 2.2 & 81.2 & 5.6 & 80.6 & 9.8 & 96.4 & 4.6 & 1.0 & 0.1 \\
MC-LR & 79.5 & 2.5 & 95.1 & 5.3 & 97.8 & 7.4 & 98.5 & 4.8 & 0.5 & 0.0 \\
MC-FR & 66.8 & 12.4 & 97.6 & 6.9 & 107.2 & 7.2 & 97.8 & 7.0 & 0.6 & 0.0 \\
MC-WR & 74.9 & 2.2 & 98.5 & 6.6 & 114.7 & 7.9 & 97.8 & 8.5 & 0.5 & 0.0 \\
MC-RA & 87.7 & 5.5 & 104.8 & 6.6 & 98.0 & 4.3 & 97.3 & 4.2 & 0.6 & 0.1 \\
MC-Raba & 105.9 & 0.0 & 108.7 & 10.9 & 102.3 & 7.4 & 100.0 & 6.2 & 0.0 & 0.0 \\
MC-LA & 76.0 & 2.1 & 72.6 & 7.1 & 57.9 & 5.6 & 93.6 & 2.8 & 0.8 & 0.0 \\
MC-FA & 67.9 & 3.3 & 81.6 & 8.5 & 62.2 & 3.7 & 93.1 & 4.7 & 1.0 & 0.1 \\
MC-WA & 75.0 & 1.4 & 87.3 & 4.6 & 70.2 & 5.6 & 95.8 & 1.8 & 3.1 & 1.0 \\
MC-LAba & 69.2 & 5.8 & 86.5 & 7.1 & 68.1 & 4.0 & n.d. & n.d. & n.d. & n.d. \\
MC-FAba & 68.4 & 4.6 & 86.9 & 8.5 & 78.3 & 2.5 & n.d. & n.d. & n.d. & n.d. \\
MC-WAba & 71.9 & 3.0 & n.d. & n.d. & n.d. & n.d. & n.d. & n.d. & n.d. & n.d. \\
MC-LF & n.d. & n.d. & n.d. & n.d. & 77.4 & 4.7 & n.d. & n.d. & n.d. & n.d. \\
D7-MC-LR & n.d. & n.d. & 97.8 & 6.6 & 92.6 & 5.9 & n.d. & n.d. & n.d. & n.d. \\
D5-MC-LF & n.d. & n.d. & 94.8 & 6.7 & 79.1 & 3.9 & n.d. & n.d. & n.d. & n.d. \\
\hline
\end{tabular}

For the determination of the loss of the SPE procedure, MC congeners in $\mathrm{MeOH}$ solution were spiked to the sample after protein precipitation and liquid-liquid partitioning, but before the SPE procedure (Middle-Spike). Liquid-liquid partitioning was performed with $\mathrm{MC}$-spiked $\mathrm{MeOH}$, which was topped with hexane. n.d.: not determined in that particular experiment. $\mathrm{n}=3$. $\mathrm{SD}=$ standard deviation.

Liquid-Liquid Partitioning (LLP) experiments, carried out according to a previously published methodology [31] to remove hydrophobic matrix elements, were conducted to determine MC congener loss during LLP. For this, an MC congener mix was spiked into methanol (MeOH), which was subsequently overlaid with n-hexane, as in the extraction procedure (Figure 2). After $30 \mathrm{~min}$, the n-hexane phase was separated from the $\mathrm{MeOH}$ phase; both fractions were dried and re-dissolved in $\mathrm{MeOH}$, thus allowing for the determination of the distribution of MC congeners in the n-hexane and $\mathrm{MeOH}$ phases. Nearly $100 \%$ of each MC congener was found in the MeOH phase (Table 1, Figure S2), thus indicating that no, or at best, negligible, loss would occur during LLP due to the n-hexane clean-up. 
Finally, the loss during protein precipitation with $\mathrm{MeOH}$ or acetonitrile $(\mathrm{ACN})$ was investigated. Protein precipitates, spiked with an MC congener mix (Full-Spike), were extracted once (1X) or twice $(2 \times)$ with the respective solvent $(\mathrm{MeOH}$ or $\mathrm{ACN})$. The comparison of $\mathrm{MeOH}$ and $\mathrm{ACN}$ did not show a significant difference (2-way-ANOVA) in recovery (Table 2 and Figure S3). Neither was there a significant increase (2-way-ANOVA) in recovery when protein precipitates were extracted twice. Hence, all subsequent experiments were carried out with a single $\mathrm{MeOH}$ extraction of the protein precipitates. As neither the SPE nor the LLP resulted in a demonstrable loss of MC congeners (Table 1), the poor recovery observed when the complete extraction procedure was followed through (Table 2), i.e., including the initial protein precipitation step suggested that the protein precipitation itself was responsible for the high loss (poor recovery) of MC congeners observed.

Table 2. Total recovery of the extraction using different protein precipitation (PP) procedures.

\begin{tabular}{|c|c|c|c|c|c|c|c|c|}
\hline & \multicolumn{4}{|c|}{ Methanol } & \multicolumn{4}{|c|}{ Acetonitrile } \\
\hline & \multicolumn{2}{|c|}{$1 \times$} & \multicolumn{2}{|c|}{$2 \times$} & \multicolumn{2}{|c|}{$1 \times$} & \multicolumn{2}{|c|}{$2 \times$} \\
\hline & Mean & SEM & Mean & SEM & Mean & SEM & Mean & SEM \\
\hline MC-RR & 43.2 & 2.1 & 52.3 & 5.0 & 44.6 & 2.6 & 47.1 & 2.8 \\
\hline MC-YR & 35.1 & 2.2 & 47.4 & 7.1 & 43.8 & 4.2 & 47.2 & 3.0 \\
\hline MC-LR & 43.8 & 2.3 & 49.4 & 5.2 & 45.9 & 2.8 & 46.7 & 2.6 \\
\hline MC-FR & 44.3 & 2.3 & 56.3 & 6.0 & 50.8 & 2.9 & 52.1 & 3.5 \\
\hline MC-WR & 41.0 & 3.0 & 54.0 & 5.6 & 45.6 & 3.3 & 48.0 & 3.2 \\
\hline MC-RA & 50.9 & 2.2 & 62.0 & 7.5 & 54.8 & 2.5 & 55.7 & 2.7 \\
\hline MC-Raba & 52.9 & 3.7 & 62.5 & 7.3 & 54.5 & 2.3 & 59.9 & 2.4 \\
\hline MC-LA & 49.2 & 2.4 & 35.2 & 3.5 & 54.2 & 2.7 & 47.7 & 3.6 \\
\hline MC-FA & 47.5 & 2.3 & 41.8 & 4.4 & 55.2 & 2.4 & 50.7 & 1.8 \\
\hline MC-WA & 45.7 & 2.6 & 49.0 & 3.8 & 48.7 & 2.5 & 50.2 & 3.7 \\
\hline MC-LAba & 49.7 & 2.8 & 47.0 & 6.0 & 57.7 & 3.0 & 56.6 & 3.3 \\
\hline MC-FAba & 50.9 & 2.2 & 52.9 & 6.0 & 59.4 & 2.5 & 64.7 & 3.6 \\
\hline MC-WAba & 0.0 & 0.0 & 0.0 & 0.0 & 0.0 & 0.0 & 0.0 & 0.0 \\
\hline MC-LF & 59.2 & 5.3 & 61.1 & 5.8 & 69.0 & 6.4 & 64.3 & 6.2 \\
\hline $\mathrm{D}_{7}$-MC-LR & 48.0 & 2.2 & 51.9 & 4.1 & 51.0 & 2.6 & 51.0 & 2.9 \\
\hline $\mathrm{D}_{5}-\mathrm{MC}-\mathrm{LF}$ & 61.0 & 2.5 & 67.4 & 6.0 & 70.0 & 3.1 & 71.6 & 3.3 \\
\hline
\end{tabular}

n.d.: not determined in that particular experiment. $\mathrm{n}=2(\mathrm{MeOH})$ and $3(\mathrm{ACN})$. SEM = standard error of the mean.

\subsection{Use of Internal Standard}

$\mathrm{D}_{5}$-MC-LF and $\mathrm{D}_{7}-\mathrm{MC}-\mathrm{LR}$ presented with similar total recovery as their respective non-deuterated analogues ( $t$-test, $p=0.31 \mathrm{MC}$-LR vs. $\mathrm{D}_{7}$-MC-LR and $p=0.79$ MC-LF vs. $\mathrm{D}_{5}$-MC-LF) (Table 2). Thus, use of these synthetic congeners could serve as an IS with which the recovery of individual MC congeners could be corrected. Hence, human serum was spiked with the MC congener mix, extracted with the established procedure (see above) and analysed using UPLC-MS/MS (Figure 3). Quantification of MC congeners without the IS for correction (Figure 3A) yielded the same result as obtained before, i.e., low recovery, thus demonstrating the robustness of the extraction and analytical procedure. When $\mathrm{D}_{5}-\mathrm{MC}$-LF was used to quantify all other MC congeners (Figure 3B), recovery for non-arginine MCs was improved from around $40 \%$ to $80 \%$; however, most arginine-containing congeners were overestimated. For example, when $10 \mu \mathrm{g} / \mathrm{mL}$ of $\mathrm{D}_{5}-\mathrm{MC}-\mathrm{LF}$ were spiked to the sample, the resulting LC-MS/MS peak value was set as $100 \%$, i.e., as if $100 \%$ recovery was achieved, and thus a correction factor for extraction loss was applied. The latter meaning that for the MC congeners to be determined the actual loss experienced during the extraction procedure was assumed to be identical to the loss observed for the IS. Accordingly, the actual values of the MC congeners to be determined were then multiplied with the correction factor for extraction loss as determined with the IS. In contrast, when $\mathrm{D}_{7}$-MC-LR (Figure 3C) was employed as IS, the recovery of arginine-containing congeners increased to $80-110 \%$, whereas non-arginine-containing congeners were limited to a recovery of approximately $60 \%$. The best results, i.e., recovery of most MC congeners of $100 \pm 20 \%$, were achieved when using a 
combination of $\mathrm{D}_{5}-\mathrm{MC}$-LF and $\mathrm{D}_{7}$-MC-LR as IS (Figure 3D), whereby $\mathrm{D}_{5}-\mathrm{MC}$-LF was employed for the correction of the recoveries of non-arginine-containing and $\mathrm{D}_{7}-\mathrm{MC}$-LR for arginine-containing $\mathrm{MC}$ congeners, respectively.
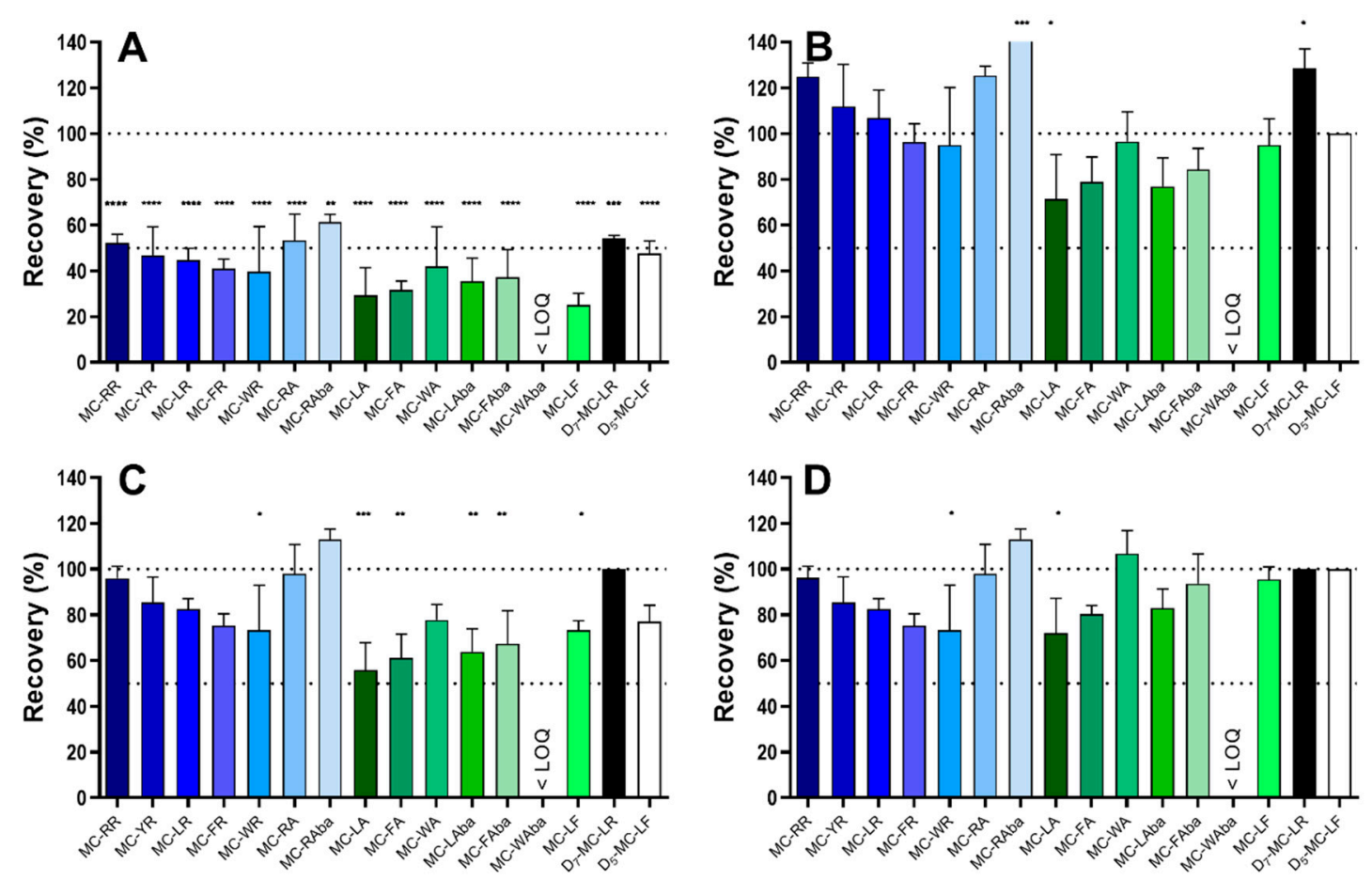

Figure 3. Quantification of MC in spiked human serum using $\mathrm{D}_{5}-\mathrm{MC}-\mathrm{LF}$ and $\mathrm{D}_{7}-\mathrm{MC}-\mathrm{LR}$ as internal standards (ISs). The same dataset was analysed using different IS for the quantification of the other MC congeners. (A) No internal standard specified, (B) $\mathrm{D}_{5}$-MC-LF as IS, (C) $\mathrm{D}_{7}-\mathrm{MC}-\mathrm{LR}$ as IS, (D) $\mathrm{D}_{7}$-MC-LR as IS for all arginine-containing congeners and $\mathrm{D}_{5}$-MC-LF for non-arginine-containing congeners. $\mathrm{n}=3$, Two-way ANOVA with Bonferroni Post-test to test difference from $100 \pm 20 \%$. ${ }^{*} p<0.05,{ }^{* *} p<0.01$, *** $p<0.001,{ }^{* * * *} p<0.0001$.

\subsection{Method Validation}

The established extraction procedure and UPLC-MS/MS detection method using deuterated MC ISs, developed for human serum (see above), was further tested by spiking murine serum and liver homogenate with the MC congener mix (Table 3). MC recoveries from mouse serum were similar to those observed for human serum regarding total recovery (Figure 3D vs. Table 3). In contrast, the recoveries from the more complex liver homogenate matrix provided mixed results. While, generally, arginine-containing MC congeners were recovered with an equally good recovery as those observed in murine serum, the recovery for some of the non-arginine-containing congeners, with the exception of MC-LF, ranged between $1 / 3$ and $\frac{1}{2}$ of the recoveries found for the respective MC congener in murine serum (Table 3).

MC-RR, MC-YR and MC-LR were used as external standards, as recommended by the European Medicines Agency (EMA) [33], to determine the LOD, LOQ and linear range for the UPLC-MS/MS detection method used. LOD was defined as the minimal amount of the analyte which provided for a discernible peak, while LOQ was defined as the minimal amount of the analyte which produced a peak at least three times higher than the background (signal above noise) and has an accuracy $< \pm 20 \%$. The LOD for each was slightly lower, i.e., $0.5 \mathrm{ng} / \mathrm{mL}$ for MC-RR and -YR and $0.1 \mathrm{ng} / \mathrm{mL}$ for MC-LR. The upper limit of the linear range might even be higher, but no higher concentrations were tested. The linear range was defined to lie between the LOQ and the highest standard concentration used in the experiment. Linear range for the three MC congeners was between 2 and $500 \mathrm{ng} / \mathrm{mL}$, all with $\mathrm{R}^{2}>0.99$. 
Table 3. Validation parameters of the established methods.

\begin{tabular}{cccccc}
\hline & \multicolumn{2}{c}{$\begin{array}{c}\text { Mouse Recovery (\% of } \\
\text { Expected Result) }\end{array}$} & LOD (ng/mL) & LOQ (ng/mL) & $\begin{array}{c}\text { Linear Range } \\
\text { (ng/mL) }\end{array}$ \\
\hline Congener & Mouse Serum & Mouse Liver & Mouse Serum & Mouse Serum & Mouse Serum \\
\hline MC-RR & $74.2 \%$ & $78.7 \%$ & 0.5 & 2 & $2-500$ \\
MC-YR & $88.5 \%$ & $82.9 \%$ & 0.5 & 2 & $2-500$ \\
MC-LR & $113.1 \%$ & $81.2 \%$ & 0.1 & 2 & $2-500$ \\
\hline MC-FR & $124.3 \%$ & $86.3 \%$ & - & - & - \\
MC-WR & $108.6 \%$ & $94.5 \%$ & - & - & - \\
MC-RA & $111.2 \%$ & $120.9 \%$ & - & - & - \\
MC-RAba & $106.4 \%$ & $109.6 \%$ & - & - & - \\
MC-LA & $86.1 \%$ & $64.5 \%$ & - & - & - \\
MC-FA & $100.0 \%$ & $43.4 \%$ & - & - & - \\
MC-WA & $96.8 \%$ & $34.1 \%$ & - & - & - \\
MC-LAba & $94.3 \%$ & $42.2 \%$ & - & - & - \\
MC-FAba & $97.4 \%$ & $54.4 \%$ & - & - & $(2-500)$ \\
MC-WAba & $89.8 \%$ & $<$ LOQ & - & - & - \\
MC-LF & $83.5 \%$ & $90.6 \%$ & $(0.5)$ & - & \\
D $\%$-MC-LR & $100.0 \%$ & $100.0 \%$ & - & - & - \\
D -MC-LF & $100.0 \%$ & $100.0 \%$ & - & - & - \\
\hline
\end{tabular}

MC-RR, MC-YR and MC-LR were used as external standards. MC-LF was also part of the external standard mix, but was not used to quantify any of the other MC congeners as it was no certified reference material but served as reference for more hydrophobic congeners. $D_{7}-M C-L R$ and $D_{7}-M C-L R$ were used as internal standards in every sample quantified. Recovery was calculated using the external standards in $\mathrm{MeOH}$. Therefore, the recovery as calculated here shows the influence of the matrix. MC congener mix spiked mouse plasma and liver homogenates from untreated male animals were used for this experiment. Linear regressions for the linearity determination all showed $\mathrm{R}^{2}>0.99$.

To determine the precision of the UPLC-MS/MS detection method, intra-day and inter-day precision was determined. Identical samples were measured on two different days. Relative standard deviations (RSD) between 1.7 and 19.7\% were observed for intra-day precision of day 1, although slightly higher similar RSDs (between 5.0 and 21.5\%) were found on day 2. No obvious relationship between RSD and MC congener structure could be observed, i.e., precision for arginine-containing congeners and non-arginine-containing congeners was similar (Table 4). When means of the individual days were compared (inter-day precision), RSD ranged from $1.3 \%$ to $31.0 \%$, again with no difference in variability among arginine- and non-arginine containing congeners (Table 4).

Table 4. Intra-day and inter-day precision.

\begin{tabular}{cccccccc}
\hline & \multicolumn{2}{c}{ Day 1 } & & & Day 2 & \multicolumn{2}{c}{ Both Days } \\
\hline & Mean (ng/mL) & SD (ng/mL) & RSD (\%) & Mean (ng/mL) & SD (ng/mL) & RSD (\%) & RSD (\%) \\
\hline MC-RR & $\mathbf{1 9 3 . 0}$ & $\mathbf{1 0 . 0}$ & $\mathbf{5 . 2}$ & $\mathbf{2 0 8 . 3}$ & $\mathbf{4 4 . 7}$ & $\mathbf{2 1 . 5}$ & $\mathbf{5 . 4}$ \\
MC-YR & $\mathbf{3 1 . 1}$ & $\mathbf{3 . 4}$ & $\mathbf{1 0 . 8}$ & $\mathbf{3 2 . 7}$ & $\mathbf{6 . 5}$ & $\mathbf{1 9 . 9}$ & $\mathbf{3 . 5}$ \\
MC-LR & $\mathbf{5 0 2 . 7}$ & $\mathbf{2 2 . 8}$ & $\mathbf{4 . 5}$ & $\mathbf{6 8 2 . 9}$ & $\mathbf{4 4 . 0}$ & $\mathbf{6 . 4}$ & $\mathbf{2 1 . 5}$ \\
\hline MC-FR & 271.9 & 14.5 & 5.3 & 383.0 & 43.5 & 11.4 & 24.0 \\
MC-WR & 81.6 & 16.1 & 19.7 & 127.3 & 16.9 & 13.3 & 31.0 \\
MC-RA & 73.5 & 9.4 & 12.8 & 75.8 & 13.5 & 17.8 & 2.2 \\
MC-RAba & 21.1 & 1.0 & 4.5 & 22.6 & 2.7 & 12.1 & 5.0 \\
MC-LA & 112.6 & 17.9 & 15.9 & 102.9 & 8.6 & 8.3 & 6.4 \\
MC-FA & 145.5 & 2.4 & 1.7 & 119.6 & 6.0 & 5.0 & 13.8 \\
MC-WA & 46.3 & 3.1 & 6.7 & 38.0 & 5.5 & 14.6 & 14.0 \\
MC-LAba & 89.0 & 10.2 & 11.5 & 87.4 & 6.5 & 7.4 & 1.3 \\
MC-FAba & 49.7 & 8.1 & 16.2 & 39.1 & 3.1 & 8.0 & 16.9 \\
MC-WAba & $<$ LOQ & n.d. & n.d. & $<$ LOQ & n.d. & n.d. & n.d. \\
MC-LF & LOQ & n.d. & n.d. & $<$ LOQ & n.d. & n.d. \\
D7-LR & 10.0 & 0.0 & 0.0 & 10.0 & 0.0 & 0.0 & n.d. \\
D5-LF & 10.0 & 0.0 & 0.0 & 10.0 & 0.0 & 0.0 \\
\hline
\end{tabular}

Samples $(n=3)$ were measured on day 1 . RSD is a measure for intraday precision. Identical samples were also measured on day 2 with slightly different RSD. The last column shows the RSD when the means of day 1 and day 2 are used. 


\subsection{Levels in Exposed Mice}

Liver and plasma samples of male and female Balb/c mice that were treated i.p. with $100 \mu \mathrm{g} / \mathrm{kg} \mathrm{bw}$ MC-LR or MC-LF before sacrifice ( $24 \mathrm{~h}$ post-injection), were analysed using the extraction procedure and UPLC-MS/MS analytical method previously developed. While MC-LF was quantifiable in plasma and liver tissue for both male and female mice (Figure 4), MC-LR was detected only in the male liver tissue but not in female livers or the plasma samples of both sexes. It is to be noted that for both MC-LF and MC-LR, toxin levels in plasma and liver appeared to be lower in females than in males. The low number of animals available for this analysis prevented further investigation, i.e., corroboration of this observation. No MCs were observed in animals injected with $20 \mu \mathrm{g} / \mathrm{kg}$ bw of the toxins every second day for two weeks (data not shown).

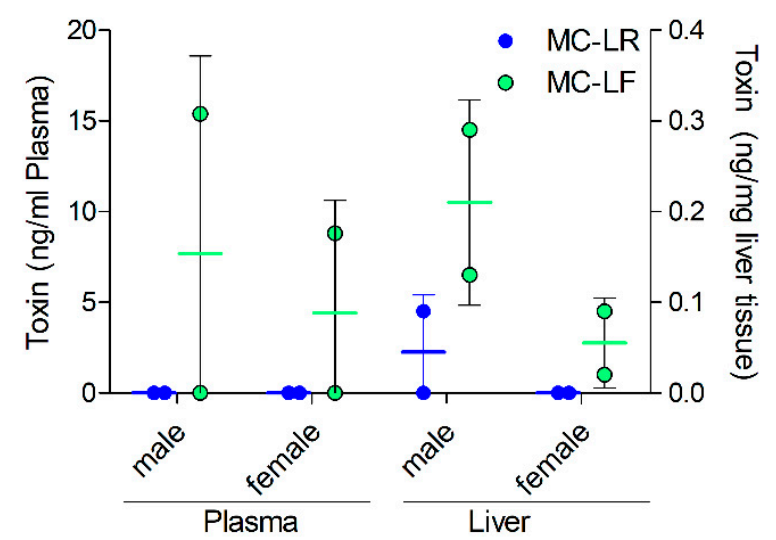

Figure 4. Analysis of MC levels in plasma and livers of exposed mice. Mice were injected with $100 \mu \mathrm{g} / \mathrm{kg}$ bw MC-LR or MC-LF. Values < LOD are shown as 0 . Results are mean \pm SD of two animals.

\section{Discussion}

The method described here demonstrated the simultaneous detection of $14 \mathrm{MC}$ congeners in biological samples (serum, plasma, liver homogenate) using synthetic deuterated MC internal standards. The complete method presented acceptable analyte recovery, low LOD and LOQ, and limited intraand inter-day variation (Tables 3 and 4). In principle, this method is also amenable to the simultaneous detection and quantification of $>14 \mathrm{MC}$ congeners, albeit this would come at the expense of decreased sensitivity for individual MC congeners, as per time unit more parent masses would need to be analysed. The latter could be partly alleviated by narrowing the specific windows of analysis, as described in the Methods section and shown in Table 5.

The quantification method presented here using two synthetic deuterated MCs as internal standards is, to the best of our knowledge, the first time this has been carried out for MCs. Previous studies have either employed MC-LR with an attached thiol group at the Mdha residue as an internal standard for the HPLC-MS analysis of MC-LR, -RR and -LA [27], or similarly thiolised MC-LR and -RR in conjunction with MALDI-MS [26]. The problem with the latter approach is that thiolised internal standards do not necessarily have the same behaviour during extraction and analysis as the parent compounds. Moreover, these ISs are based on arginine-containing MC congeners, thus introducing a bias when measuring non-arginated MC congeners. In contrast, the ISs used here ( $\mathrm{D}_{5}-\mathrm{MC}$-LF and $\mathrm{D}_{7}-\mathrm{MC}-\mathrm{LR}$ ) represent two major classes of MC, i.e., arginated and non-arginated congeners, and more importantly do not incorporate structural changes of the IS that would change behaviour during extraction and analysis. Other studies have suggested that heavy atoms are the best choice for labelling, because deuterium may change the analytical properties of the standards, e.g., retention time and hydrophobicity, possibly leading to altered recovery [34,35]. However, this was not observed during the present study with recovery (Supplementary Figures S1 and S3) and 
retention times being indistinguishable from those observed for the respective naturally occurring (non-deuterated) MC congeners.

Although the new procedure for quantifying MC congeners in biological tissue samples is promising, it must be noted that the analysis is still restricted to free and unconjugated MC congeners, as it uses the parent ion mass of each congener analysed. It has been suggested that free MC only comprises a minor portion of the total MC load after exposure [2,36], so one would assume that the actual MC load is severely underestimated [19]. Indeed, MC-LR was nearly undetectable in liver and plasma of mice injected i.p., with $100 \mu \mathrm{g} / \mathrm{kg}$ bw of MC-LR (Figure 4). While the lack of MC-LR detection in plasma samples could be interpreted to be the result of rapid uptake via the mOatp1b2 [37,38], lack of MC-LR detection in the liver samples could suggest either covalent protein binding or rapid excretion, and thus elimination from the liver. Indeed, as MC-LF was detectable in the liver samples and the covalent interaction of MC-LF and MC-LR are assumed to be comparable, it is currently undiscernible whether the differences of liver tissue levels stem from differences in kinetics (uptake and excretion of MC congeners), dynamics (covalent binding) or indeed difference in extraction of free and protein bound MC. Recently, methods have been developed that are capable of cleaving the thiol bond formed during conjugation and thus release free MC using basic conditions [39-41]. Moreover, the regioselective cleavage of the thiol bond in combination with the application of our IS to future in vivo or in vitro experiments would allow to quantify the amount of free, conjugated and protein-bound single MC congeners or MC congener mixtures.

ESI-MS/MS methods are known to be influenced by matrix components left in the sample subsequent to extraction (matrix-effects) [42]. Although ISs were employed, the matrix still influenced the signal of the individual MC congeners. It is interesting to note that the liver matrix appeared to influence the recovery of the non-arginated MC congeners MC-LA, MC-FA, MC-WA, MC-LAba, MC-FAba, and MC-WAba (34.1-64.5\% recovery) more profoundly than other non-arginated (MC-LF, $90.6 \%$ ) or arginated MC congeners (78.7-120.9\% recovery) (Table 3).

Ideally, method validation would be carried out with human and murine serum and plasma, albeit no marked difference was observed between the application of the method on human or mouse serum (Figure 3D vs. Table 3). Nevertheless, previous studies suggested stronger binding of MC congeners to human than to murine or other mammalian albumin $[43,44]$, thus the recoveries obtained for 14 MC congeners in human serum (Figure 3) with those observed in murine plasma (Figure 4, Table 3) would suggest that the differences in albumin binding had an impact. In consequence, method validation would have to be carried out for every sample type prior to broad data analysis.

As method validation was carried out in murine plasma, more trust is placed in the results of the plasma analyses of the mouse experiments in vivo than in those in the liver homogenates. Irrespective of the latter, MC could not be detected in plasma or liver tissue of mice which were injected with $20 \mu \mathrm{g} / \mathrm{kg}$ bw MC-LR or MC-LF every second day for 2 weeks, while mice exposed to $100 \mu \mathrm{g} / \mathrm{kg} \mathrm{bw}$ MC-LR and LF showed detectable MC levels both in plasma and liver tissue (Figure 4). Studies in humans $[45,46]$ observed serum levels of around $0.2-0.6 \mathrm{ng} / \mathrm{mL}$ in humans consuming contaminated food items and drinking water. Here, we could detect MCs in mouse plasma at around 10-15 ng/mL after injection of a single dose $100 \mu \mathrm{g} / \mathrm{kg}$ bw. This shows, that the detection limit is biologically relevant and that the range in which the presented method is linear fits to actually observed levels. MCs are known to be efficiently conjugated to glutathione [47] and are subsequently rapidly excreted [48,49], most likely via the bile into the small intestine. Thus, it may not be surprising that application of small concentrations of MCs every two days for 2 weeks resulted in non-detectable free MC in the plasma and liver of exposed mice. If a regioselective cleavage of the thiol bond had been applied to the plasma and liver homogenates prior to the MC extraction procedure, protein-bound MC would most likely have been detected. Indeed, a recent study in pigs showed that oral consumption via drinking water over several weeks at low MC-LR doses $(2 \mu \mathrm{g} / \mathrm{kg} \mathrm{bw})$ did not lead to any detectable free microcystins in plasma and livers, similar to our study. However protein-bound MC-LR could be detected in the livers at around $20 \mathrm{ng} / \mathrm{mg}$ using Lemieux oxidation [50]. Thus, the implementation of regioselective 
cleavage to assess the fraction of bound MCs is essential, especially as it was found that around $85 \%$ of administered MC-LR amounts are found in a bound state in fish tissue [19].

The fact that MC-LF was readily detectable in plasma and liver homogenates of male and female mice, whereas this was not the case for MC-LR, could suggest that either the murine Oatp1b2 expressed in the liver is more proficient in taking up MC-LR than MC-LF or that murine hepatocytes conjugate and excrete MC-LR faster than MC-LF. Differences in binding affinity of MC-LF and-LR for the murine organic anion polypeptide transporter mOatp1b2 have been observed [37,38]. Interestingly, females tended to show lower detectable amounts of MC-LF in both matrices than males, an observation that could stem from a sex-dependent expression levels of Oatp1b2 which is hormonally regulated, as observed for other murine Oatps [44,51]. However, the latter findings need to be taken with caution, as only two replicates were used. Nevertheless, similar quantities of MC-LR, based on wet weight, were found in livers of the mice in our study when compared to the livers of rats used in the study of Wang, Xie, Chen and Liang [48].

In summary, we established a procedure capable of simultaneously quantifying $14 \mathrm{MC}$ congeners in plasma/serum and liver tissue samples. For the first time, de novo synthesised deuterated MC internal standards were used for quantification and resulted in a highly improved recovery of MC congeners. The method was validated using a matrix of plasma and was applied to the detection of administered $\mathrm{MC}$ in mouse plasma and liver samples. In the future, the regioselective cleavage of the thiol bond in combination with the application of our deuterated ISs should allow for the quantification of free, conjugated (e.g., glutathione) and protein-bound single MC congeners or MC congener mixtures.

\section{Materials and Methods}

\subsection{Materials}

Human serum (off the clot) was obtained from Biochrom (Berlin, Germany) or from the New Zealand Blood Service. Water was deionised water with 18.2 M $\Omega$ (Milli-Q). Formic acid (Merck, Darmstadt, Germany), acetonitrile (Carl Roth, Karlsruhe, Germany) and solvents were of MS grade. Analytical standards for MC-RR, MC-LR and MC-YR were from DHI LAB products (Hørsholm, Denmark). SPE columns were either from Waters (Oasis HLB and PRiME HLB, Eschborn, Germany) or from Phenomenex (StrataX, Auckland, New Zealand). They were used with a vacuum manifold by Macherey-Nagel (Düren, Germany).

For UPLC-MS/MS analytics, an internal standard was used which comprised synthetic, deuterated MC-LR and MC-LF. The synthesis of $\mathrm{D}_{5}-\mathrm{MC}-\mathrm{LF}$ (containing phenylalanine with a deuterated phenyl group (five D-atoms) in position 4) was published previously [52]. $\mathrm{D}_{7}$-MC-LR was synthesised in analogy to the published synthesis of $\mathrm{D}_{5}$-MC-LF employing leucine deuterated in the side chain (seven D-atoms) at position 2. These two standards were either used for spiking mouse plasma and liver samples (see below), or supplementing (100 $\mathrm{ng} / \mathrm{mL}$ each) a mixture of MCs (MC-mix) extracted from Microcystis CAWBG11 cells as published previously [28,32]. The extract contained multiple microcystin congeners, among them MC-RR, -YR, -LR, -FR, - WR, -RA, -RAba, -LA, -FA, -WA, -LAba, -FAba, -WAba and was additionally supplemented with each $100 \mathrm{ng} / \mathrm{mL}$ MC-LF. The so-produced stock solution (MC congener mix) was used for spiking into samples at a 1:10 ratio to establish the extraction and detection method. MC concentrations ranged between $94 \mathrm{ng} / \mathrm{mL}$ (MC-WAba) and $2768 \mathrm{ng} / \mathrm{mL}$ (MC-LR) in the stock solution.

\subsection{Sample Generation for the Establishment and Validation}

All liquid samples were handled in glass LC-vials to reduce loss due to adsorption, as previously recommended [31,32].

Serum/plasma samples for method establishment $(0.5 \mathrm{~mL})$ were spiked with MC congener mix stock at a 1:10 ratio (MC mix:serum, vol/vol). A 1:10 dilution of the MC mix in methanol, serving as control for every experiment, was analysed without further treatment (Recovery control). Spiking was performed at 
different steps during the procedure (Figure 2); before extraction (Full-Spike), after extraction but before UPLC-MS/MS analysis (Over-Spike) or directly before the SPE step (Middle-Spike). These samples were used for generating the data in Tables 1 and 2, and Figure 3.

Additional establishment and validation experiments were performed with plasma and livers of non-treated Balb/c mice obtained from the animal facility of the University of Konstanz. Serum/plasma $(0.25 \mathrm{~mL})$ was used as is, while liver samples were homogenised prior to spiking. For homogenisation, livers were thawed on ice, pieces taken, weighed, and 200\% ice-cold RIPA buffer was added (e.g., $125 \mathrm{mg}$ liver $+250 \mu \mathrm{L}$ RIPA). The sample was then homogenised using an electric drill with attached pestle while on ice. The final liver homogenate $(250 \mu \mathrm{L})$ was used for spiking and subsequent toxin extraction, resulting in $83.3 \mathrm{mg}$ of tissue used for one sample. Spiking was carried out with the MC-congener mix at a ratio of 1:10 ( $\mathrm{vol} / \mathrm{vol})$. These samples were used during the method validation (Table 3).

\subsection{Extraction Method for MC from Blood and Liver Tissue Samples}

Samples ( $250 \mu \mathrm{L}$ liver homogenates or plasma/serum) were transferred to glass reaction tubes and subjected to protein precipitation by adding three volumes $100 \% \mathrm{MeOH}$. Precipitates were centrifuged for $40 \mathrm{~min}$ at $4{ }^{\circ} \mathrm{C}$ with $3023 \mathrm{rcf}$. Subsequently, supernatants were transferred to clean glass tubes. Removal of lipophilic compounds from the supernatant was conducted using n-hexane (4 mL). Samples were vortexed, phases were allowed to separate for $30 \mathrm{~min}$ before the n-hexane was removed and discarded. The sample was diluted with MilliQ (52 volumes) to reduce the organic solvent content below $10 \%(v / v)$ in the final sample. Afterwards, samples were subjected to solid-phase extraction (SPE) clean-up using Waters Oasis HLB (6 cc, $200 \mathrm{mg}$ sorbent). Columns were connected to a vacuum manifold, activated with $100 \% \mathrm{MeOH}(5 \mathrm{~mL})$ and equilibrated with $10 \% \mathrm{MeOH}(5 \mathrm{~mL})$. Then the sample was loaded, washed with MilliQ $(7 \mathrm{~mL})$ and $20 \% \mathrm{MeOH}(7 \mathrm{~mL})$ before elution with $80 \% \mathrm{MeOH}$ $(5 \mathrm{~mL})$. All SPE steps were performed at a maximum vacuum of $20 \mathrm{kPa}$. SPE eluents were dried with a SpeedVac before reconstitution in 0.25 or $0.5 \mathrm{~mL}$ pure $\mathrm{MeOH}$ and stored at $-20{ }^{\circ} \mathrm{C}$ until analysis. Samples of the animal study had to be concentrated further. In the latter case, samples were again dried using the SpeedVac and reconstituted in $12.5 \mu \mathrm{L}$ pure $\mathrm{MeOH}$.

\subsection{UPLC-MS/MS Analysis}

Analyses were performed on a Waters Acquity H-class liquid chromatograph equipped with an Acquity BEH C18 column $(1.6 \mu \mathrm{m}, 2.1 \times 50 \mathrm{~mm})$ with a corresponding guard column kept at $40{ }^{\circ} \mathrm{C}$, coupled to a Waters XEVO TQ-S mass spectrometer. The used solvents were $10 \% \mathrm{ACN}$ (solvent $\mathrm{A}$ ) and $90 \% \mathrm{ACN}$ (solvent B), both containing $100 \mathrm{mM} \mathrm{CH}_{2} \mathrm{O}_{2}$ and $6 \mathrm{mM} \mathrm{NH}_{3}$ with a total flow of $0.4 \mathrm{~mL} / \mathrm{min}$. The used gradient started with $25 \% \mathrm{~B}$, held for $30 \mathrm{~s}$ at $25 \% \mathrm{~B}$ before increasing to $45 \% \mathrm{~B}$ over additional $30 \mathrm{~s}$. Over the following $180 \mathrm{~s}$ amount of solvent B increased to $60 \%$ before being raised to $99 \%$ over $12 \mathrm{~s}$ where it was held for additional $30 \mathrm{~s}$. Reequilibration back to $25 \% \mathrm{~B}$ was done over $78 \mathrm{~s}$, where it was held for another $60 \mathrm{~s}$ before the next sample injection. Injection volume was $5 \mu \mathrm{L}$. Compounds were ionised using a capillary voltage of $3 \mathrm{kV}$ and a nebuliser pressure of 7.0 bar. Dissolution was achieved using a nitrogen flow of $1000 \mathrm{~L} / \mathrm{h}$ at $500{ }^{\circ} \mathrm{C}$. Analysis of the congeners was divided into five analysis windows, to reduce the number of parallel analysed congeners in order to maximise the time spent scanning for each individual compound. Analysis parameters for all MC congeners are shown in Table 5 .

MC-RR, MC-YR and MC-LR were used as external standards for each analytical run. Standards were used at three final concentration levels: 2,10 and $100 \mathrm{ng} / \mathrm{mL}$ and employed for establishing a linear regression of the signal response with the injected amount. In the first experiments, these standards were used in $\mathrm{MeOH}$, during method validation standards were used in blank extracted matrix. The external standard MC congener mix also contained MC-LF, which was not from a source classified as reference material. Therefore, it was not used to quantify any MC levels, but only as a point of comparison to the other standards during the validation. $\mathrm{D}_{7}-\mathrm{MC}-\mathrm{LR}$ as IS for all arginine-containing congeners and $\mathrm{D}_{5}$-MC-LF for non-arginine-containing congeners were either spiked into samples 
individually before extraction (animal experiment) or were part of the MC-mix used for establishment and validation.

Table 5. MS Parameters.

\begin{tabular}{|c|c|c|c|c|c|c|c|c|}
\hline Congener & $\begin{array}{c}\text { Analysis } \\
\text { Window (min) }\end{array}$ & $\begin{array}{c}\text { Parent } \\
\text { Mass }(m / z)\end{array}$ & $\begin{array}{c}\text { Daughter } \\
\text { Mass }(m / z)\end{array}$ & $\begin{array}{c}\text { Dwell } \\
\text { Time (s) }\end{array}$ & $\begin{array}{c}\text { Cone } \\
\text { Voltage (V) }\end{array}$ & $\begin{array}{c}\text { Collision } \\
\text { Energy (V) }\end{array}$ & $\begin{array}{c}\text { External } \\
\text { Standard }\end{array}$ & $\begin{array}{c}\text { Internal } \\
\text { Standard }\end{array}$ \\
\hline MC-RR & $0.3-1.6$ & 519.7 & 135.1 & 0.027 & 40 & 27 & MC-RR & $\mathrm{D}_{7}-\mathrm{MC}-\mathrm{LR}$ \\
\hline MC-YR & $0.3-1.6$ & 1045.6 & 135.1 & 0.027 & 40 & 70 & MC-YR & $\mathrm{D}_{7}-\mathrm{MC}-\mathrm{LR}$ \\
\hline MC-LR & $0.3-1.6$ & 995.6 & 135.1 & 0.027 & 40 & 65 & MC-LR & $\mathrm{D}_{7}-\mathrm{MC}-\mathrm{LR}$ \\
\hline MC-FR & $0.3-1.6$ & 1029.6 & 135.1 & 0.027 & 40 & 65 & MC-LR & $\mathrm{D}_{7}-\mathrm{MC}-\mathrm{LR}$ \\
\hline MC-WR & $0.3-1.6$ & 1086.6 & 135.1 & 0.027 & 40 & 65 & MC-LR & $\mathrm{D}_{7}-\mathrm{MC}-\mathrm{LR}$ \\
\hline MC-RA & $1.3-2.5$ & 953.6 & 135.1 & 0.024 & 40 & 65 & MC-LR & $\mathrm{D}_{7}-\mathrm{MC}-\mathrm{LR}$ \\
\hline MC-Raba & $1.3-2.5$ & 967.6 & 135.1 & 0.024 & 40 & 65 & MC-LR & $\mathrm{D}_{7}-\mathrm{MC}-\mathrm{LR}$ \\
\hline MC-LA & $1.3-2.5$ & 910.6 & 135.1 & 0.024 & 40 & 65 & MC-LR & $\mathrm{D}_{7}-\mathrm{MC}-\mathrm{LF}$ \\
\hline MC-FA & $1.3-2.5$ & 944.6 & 135.1 & 0.024 & 40 & 65 & MC-LR & $\mathrm{D}_{7}-\mathrm{MC}-\mathrm{LF}$ \\
\hline MC-WA & $1.3-2.5$ & 983.6 & 135.1 & 0.024 & 40 & 65 & MC-LR & $\mathrm{D}_{5}-\mathrm{MC}-\mathrm{LF}$ \\
\hline MC-Laba & $1.7-3.5$ & 924.6 & 135.1 & 0.024 & 40 & 65 & MC-LR & $\mathrm{D}_{5}-\mathrm{MC}-\mathrm{LF}$ \\
\hline MC-Faba & $1.7-3.5$ & 958.6 & 135.1 & 0.024 & 40 & 65 & MC-LR & $\mathrm{D}_{5}-\mathrm{MC}-\mathrm{LF}$ \\
\hline MC-WAba & $1.7-3.5$ & 997.6 & 135.1 & 0.024 & 40 & 65 & MC-LR & $\mathrm{D}_{5}-\mathrm{MC}-\mathrm{LF}$ \\
\hline MC-LF & $1.7-3.5$ & 986.6 & 135.1 & 0.024 & 40 & 65 & MC-LR & $\mathrm{D}_{5}-\mathrm{MC}-\mathrm{LF}$ \\
\hline $\mathrm{D}_{7}$-MC-LR & $1.0-1.8$ & 1002.7 & 135.1 & 0.024 & 40 & 65 & MC-LR & - \\
\hline $\mathrm{D}_{5}-\mathrm{MC}-\mathrm{LF}$ & $2.3-3.5$ & 991.6 & 135.1 & 0.024 & 40 & 65 & MC-LR & - \\
\hline
\end{tabular}

The columns for internal and external standard denominate the congeners, which are used for the quantification of the respective conger during the UPLC-MS/MS analysis. Dwell times differ as the individual analytical windows do not contain the same numbers of congeners.

\subsection{Animal Samples}

Balb/c mice, obtained from Janvier (Le Genest-Saint-Isle, France), were injected i.p. with either MC-LR, MC-LF (20 $\mu \mathrm{g} / \mathrm{kg}$ bw) or vehicle (water) every second day for 14 days, before sacrifice of the animals and organ harvest. Additional mice were injected once with $100 \mu \mathrm{g} / \mathrm{kg}$ bw MC-LF or MC-LR. Mice were sacrificed $24 \mathrm{~h}$ after last injection. Blood was taken in heparinised tubes, centrifuged and the remaining plasma was snap-frozen in liquid nitrogen. Liver tissue was also snap-frozen in liquid nitrogen. Samples were stored at $-80{ }^{\circ} \mathrm{C}$ until further preparation. Mice were housed in plastic cages, in an air-conditioned room $\left(20-23^{\circ} \mathrm{C}\right)$ under a 12/12 h light/dark cycle with free access to rodent pellets and tap water. The animals were acclimatised at least 7 days prior to experimentation. Animal handling, exposure and organ removal was performed in the laboratory of ANSES (Agence nationale de sécurité sanitaire de l'alimentation, de l'environnement et du travail) Fougères in 2008 according to approved protocols by the Institute's ethical committee on animal experimentation.

For spiking experiments, plasma samples were used as is, while livers were homogenised in analogy to the validation samples (see above). Every sample was spiked with 10-50 ng/mL $\mathrm{D}_{7}-\mathrm{MC}-\mathrm{LR}$ and $\mathrm{D}_{5}-\mathrm{MC}-\mathrm{LF}$, as IS, and samples stored at $-20^{\circ} \mathrm{C}$ until extraction.

\subsection{Data Analyses and Statistics}

LC-MS/MS data was analysed using Targetlynx 4.1 integrated into MassLynx 4.1 (Waters). Data handling was performed with Microsoft Excel, while GraphPad Prism 5 was used for statistical analysis and data visualisation.

Supplementary Materials: The following are available online at http://www.mdpi.com/2072-6651/11/7/388/s1, Figure S1: Column comparison using a middle-spike in serum, Figure S2: Distribution of microcystins in methanol and hexane fractions, Figure S3: Use of acetonitrile and methanol for protein precipitation.

Author Contributions: Conceptualisation: S.A., J.P., D.R.D. Data curation: S.A. Formal analysis: S.A. Funding acquisition: S.A., J.P., D.R.D. Investigation: S.A., V.F., D.F. Methodology: S.A., J.P., D.F., I.Z., V.W. Resources: J.P., V.F., I.Z., V.W., D.R.D. Supervision: J.P., V.W., D.R.D. Visualisation: S.A. Writing-original draft: S.A. Writing一review \& editing: S.A., J.P., V.F., I.Z., V.W., D.R.D.

Funding: This research was funded by the Arthur-and-Aenne-Feindt Foundation (Hamburg Germany), the Marie Curie International Research Staff Exchange Scheme Fellowship (PIRSES-GA-2011-295223), the Royal Society of New Zealand International Research Staff Exchange Scheme Fellowship (MEAT Agreement 295223), the Marsden 
Fund of the Royal Society of New Zealand (CAW1601), the Konstanz Research School Chemical Biology (KoRS-CB) and CHARM (Baden-Württemberg Wassernetzwerk). The UPLC-MS/MS instrument was funded through a large investment grant of the DFG INST 38-537-1.

Acknowledgments: Thanks to Jutta Fastner for the opportunity to gather very first MS/MS experience (S.A.) at the labs of the Umweltbundesamt (Berlin, Germany). Also, thanks to Michael Boundy (Cawthron Institute) for helpful insights into MS-troubleshooting. We gratefully acknowledge Tabea Zubel and Aswin Mangerich (Molecular Toxicology, University of Konstanz) for the help and troubleshooting during UPLC-MS/MS analyses.

Conflicts of Interest: The authors declare no conflict of interest.

\section{References}

1. Huisman, J.; Codd, G.A.; Paerl, H.W.; Ibelings, B.W.; Verspagen, J.M.H.; Visser, P.M. Cyanobacterial blooms. Nat. Rev. Microbiol. 2018, 16, 471-483. [CrossRef] [PubMed]

2. Azevedo, S.M.; Carmichael, W.W.; Jochimsen, E.M.; Rinehart, K.L.; Lau, S.; Shaw, G.R.; Eaglesham, G.K. Human intoxication by microcystins during renal dialysis treatment in Caruaru—Brazil. Toxicology 2002, 181-182, 441-446. [CrossRef]

3. Spoof, L.; Catherine, A. Appendix 3: Tables of Microcystins and Nodularin. In Handbook of Cyanobacterial Monitoring and Cyanotoxin Analysis; Meriluoto, J., Spoof, L., Codd, G., Eds.; John Wiley \& Sons: Hoboken, NJ, USA, 2017.

4. Fischer, W.J.; Altheimer, S.; Cattori, V.; Meier, P.J.; Dietrich, D.R.; Hagenbuch, B. Organic anion transporting polypeptides expressed in liver and brain mediate uptake of microcystin. Toxicol. Appl. Pharmacol. 2005, 203, 257-263. [CrossRef] [PubMed]

5. Fischer, A.; Hoeger, S.J.; Stemmer, K.; Feurstein, D.J.; Knobeloch, D.; Nussler, A.; Dietrich, D.R. The role of organic anion transporting polypeptides (OATPs/SLCOs) in the toxicity of different microcystin congeners in vitro: A comparison of primary human hepatocytes and OATP-transfected HEK293 cells. Toxicol. Appl. Pharmacol. 2010, 245, 9-20. [CrossRef] [PubMed]

6. Kaur, G.; Dietrich, D.R. The role of human MRP2 in cellular efflux of microcystin congeners (Poster). In Proceedings of the 57th Annual Meeting of the Society of Toxicology, San Antonio, TX, USA, 11-15 March 2018.

7. Kaur, G.; Zemskov, I.; Wittmann, V.; Dietrich, D.R. Toxicokinetics and dynamics of microcystin congeners are structure-dependent (Poster). In Proceedings of the 58th Annual Meeting of the Society of Toxicology, Baltimore, MA, USA, 10-14 March 2018.

8. Kondo, F.; Ikai, Y.; Oka, H.; Okumura, M.; Ishikawa, N.; Harada, K.; Matsuura, K.; Murata, H.; Suzuki, M. Formation, characterization, and toxicity of the glutathione and cysteine conjugates of toxic heptapeptide microcystins. Chem. Res. Toxicol. 1992, 5, 591-596. [CrossRef] [PubMed]

9. Swingle, M.; Ni, L.; Honkanen, R.E. Small Molecule Inhibitors of ser/thr protein phosphatases: Specificity, use and common forms of abuse. Methods Mol. Bio 2007, 365, 23-38. [CrossRef]

10. Garibo, D.; Flores, C.; Ceto, X.; Prieto-Simon, B.; Del Valle, M.; Caixach, J.; Diogene, J.; Campas, M. Inhibition equivalency factors for microcystin variants in recombinant and wild-type protein phosphatase 1 and $2 \mathrm{~A}$ assays. Environ. Sci. Pollut. Res. Int. 2014, 18, 10652-10660. [CrossRef] [PubMed]

11. Mattila, K.; Annila, A.; Rantala, T.T. Metals ions mediate the binding of cyanobacterial toxins to human protein phosphatase 1-A computational study. Acta Universitatis Ouluensis A 2000, A 351,31-68.

12. Fontanillo, M.; Köhn, M. Microcystins: Synthesis and structure-activity relationship studies toward PP1 and PP2A. Bioorg. Med. Chem. 2018, 26, 1118-1126. [CrossRef]

13. Sanseverino, I.; António, D.C.; Loos, R.; Lettieri, T. Cyanotoxins: Methods and Approaches for Their Analysis and Detection; Centre, J.R., Ed.; Publications Office of the European Union: Luxembourg, 2017.

14. Hawkins, P.R.; Novic, S.; Cox, P.; Neilan, B.A.; Burns, B.P.; Shaw, G.; Wickramasinghe, W.; Peerapornpisal, Y.; Ruangyuttikarn, W.; Itayama, T. A review of analytical methods for assessing the public health risk from microcystin in the aquatic environment. J. Water Supply Res. Technol. 2005, 54, 509-518. [CrossRef]

15. Gilroy, D.J.; Kauffman, K.W.; Hall, R.A.; Huang, X.; Chu, F.S. Assessing potential health risks from microcystin toxins in blue-green algae dietary supplements. Environ. Health Perspect. 2000, 108, 435-439. [CrossRef] [PubMed]

16. Niedermeyer, T. Microcystin Congeners Described in the Literature, Version 5. Available online: http://10.6084/m9.figshare.880756 (accessed on 2 May 2016). 
17. Sano, T.; Nohara, K.; Shiraishi, F.; Kaya, K. A Method for Micro-Determination of Total Microcystin Content in Waterblooms of Cyanobacteria (Blue-Green Algae). Int. J. Environ. Anal. Chem. 1992, 49, 163-170. [CrossRef]

18. Neffling, M.-R.; Lance, E.; Meriluoto, J. Detection of free and covalently bound microcystins in animal tissues by liquid chromatography-tandem mass spectrometry. Environ. Pollut. 2010, 158, 948-952. [CrossRef] [PubMed]

19. Greer, B.; Maul, R.; Campbell, K.; Elliott, C.T. Detection of freshwater cyanotoxins and measurement of masked microcystins in tilapia from Southeast Asian aquaculture farms. Anal. Bioanal. Chem. 2017, 409, 4057-4069. [CrossRef] [PubMed]

20. Mallet, C. Analysis of Microcystins RR, LY, and YR in Bottled, Tap, and Surface Water Using ACQUITY UPLC Systems with 2D-LC Technology. Available online: http://www.waters.com/waters/library.htm?cid= 511436\&lid=134826892\&locale=de_DE (accessed on 9 November 2018).

21. Turner, A.D.; Waack, J.; Lewis, A.; Edwards, C.; Lawton, L. Development and single-laboratory validation of a UHPLC-MS/MS method for quantitation of microcystins and nodularin in natural water, cyanobacteria, shellfish and algal supplement tablet powders. J. Chromatogr. B Anal. Technol. Biomed. Life Sci. 2017, 1074-1075, 111-123. [CrossRef] [PubMed]

22. Manubolu, M.; Lee, J.; Riedl, K.M.; Kua, Z.X.; Collart, L.P.; Ludsin, S.A. Optimization of extraction methods for quantification of microcystin-LR and microcystin-RR in fish, vegetable, and soil matrices using UPLC-MS/MS. Harmful Algae 2018, 76, 47-57. [CrossRef] [PubMed]

23. Greer, B.; McNamee, S.E.; Boots, B.; Cimarelli, L.; Guillebault, D.; Helmi, K.; Marcheggiani, S.; Panaiotov, S.; Breitenbach, U.; Akcaalan, R.; et al. A validated UPLC-MS/MS method for the surveillance of ten aquatic biotoxins in European brackish and freshwater systems. Harmful Algae 2016, 55, 31-40. [CrossRef] [PubMed]

24. Diez-Quijada, L.; Guzman-Guillen, R.; Prieto Ortega, A.I.; Llana-Ruiz-Cabello, M.; Campos, A.; Vasconcelos, V.; Jos, A.; Camean, A.M. New Method for Simultaneous Determination of Microcystins and Cylindrospermopsin in Vegetable Matrices by SPE-UPLC-MS/MS. Toxins 2018, 10, 406. [CrossRef]

25. Zervou, S.K.; Christophoridis, C.; Kaloudis, T.; Triantis, T.M.; Hiskia, A. New SPE-LC-MS/MS method for simultaneous determination of multi-class cyanobacterial and algal toxins. J. Hazard. Mater. 2017, 323, 56-66. [CrossRef]

26. Roegner, A.F.; Schirmer, M.P.; Puschner, B.; Brena, B.; Gonzalez-Sapienza, G. Rapid Quantitative Analysis of Microcystins in Raw Surface Waters with MALDI MS Utilizing Easily Synthesized Internal Standards. Toxicon 2014, 78, 94-102. [CrossRef]

27. Smith, J.L.; Boyer, G.L. Standardization of microcystin extraction from fish tissues: A novel internal standard as a surrogate for polar and non-polar variants. Toxicon 2009, 53, 238-245. [CrossRef] [PubMed]

28. Puddick, J.; Prinsep, M.R.; Wood, S.A.; Kaufononga, S.A.; Cary, S.C.; Hamilton, D.P. High levels of structural diversity observed in microcystins from Microcystis CAWBG11 and characterization of six new microcystin congeners. Mar. Drugs 2014, 12, 5372-5395. [CrossRef] [PubMed]

29. Turner, A.D.; Dhanji-Rapkova, M.; O’Neill, A.; Coates, L.; Lewis, A.; Lewis, K. Analysis of Microcystins in Cyanobacterial Blooms from Freshwater Bodies in England. Toxins 2018, 10, 39. [CrossRef] [PubMed]

30. Feurstein, D.; Stemmer, K.; Kleinteich, J.; Speicher, T.; Dietrich, D.R. Microcystin Congener- and Concentration-Dependent Induction of Murine Neuron Apoptosis and Neurite Degeneration. Toxicol. Sci. 2011, 124, 424-431. [CrossRef] [PubMed]

31. Heussner, A.H.; Altaner, S.; Kamp, L.; Rubio, F.; Dietrich, D.R. Pitfalls in microcystin extraction and recovery from human blood serum. Chem. Biol. Interact. 2014, 223, 87-94. [CrossRef]

32. Altaner, S.; Puddick, J.; Wood, S.A.; Dietrich, D.R. Adsorption of Ten Microcystin Congeners to Common Laboratory-Ware Is Solvent and Surface Dependent. Toxins 2017, 9, 129. [CrossRef] [PubMed]

33. EMA. Guideline on Bioanalytical Method Validation; Committee for Medicinal Products for Human Use (CHMP), Ed.; European Medicines Agency: London, UK, 2011.

34. Stokvis, E.; Rosing, H.; Beijnen, J.H. Stable isotopically labeled internal standards in quantitative bioanalysis using liquid chromatography/mass spectrometry: Necessity or not? Rapid Commun. Mass Spectrom. 2005, 19, 401-407. [CrossRef]

35. Wang, S.; Cyronak, M.; Yang, E. Does a stable isotopically labeled internal standard always correct analyte response? A matrix effect study on a LC/MS/MS method for the determination of carvedilol enantiomers in human plasma. J. Pharm. Biomed. Anal. 2007, 43, 701-707. [CrossRef] 
36. Carmichael, W.W.; Azevedo, S.; An, J.S.; Molica, R.; Jochimsen, E.M.; Lau, S.; Rinehart, K.L.; Shaw, G.R.; Eaglesham, G.K. Human fatalities from cyanobacteria: Chemical and biological evidence for cyanotoxins. Environ. Health Perspect. 2001, 109, 663-668. [CrossRef]

37. Feurstein, D.; Holst, K.; Fischer, A.; Dietrich, D.R. Oatp-associated uptake and toxicity of microcystins in primary murine whole brain cells. Toxicol. Appl. Pharmacol. 2009, 234, 247-255. [CrossRef]

38. Lu, H.; Choudhuri, S.; Ogura, K.; Csanaky, I.L.; Lei, X.; Cheng, X.; Song, P.Z.; Klaassen, C.D. Characterization of organic anion transporting polypeptide 1b2-null mice: Essential role in hepatic uptake/toxicity of phalloidin and microcystin-LR. Toxicol. Sci. 2008, 103, 35-45. [CrossRef] [PubMed]

39. Zemskov, I.; Kropp, H.M.; Wittmann, V. Regioselective Cleavage of Thioether Linkages in Microcystin Conjugates. Chem. Eur. J. 2016, 22, 10990-10997. [CrossRef] [PubMed]

40. Miles, C.O. Rapid and Convenient Oxidative Release of Thiol-Conjugated Forms of Microcystins for Chemical Analysis. Chem. Res. Toxicol. 2017, 30, 1599-1608. [CrossRef] [PubMed]

41. Miles, C.O.; Sandvik, M.; Nonga, H.E.; Ballot, A.; Wilkins, A.L.; Rise, F.; Jaabaek, J.A.; Loader, J.I. Conjugation of Microcystins with Thiols is Reversible: Base-Catalyzed Deconjugation for Chemical Analysis. Chem. Res. Toxicol. 2016, 860-870. [CrossRef] [PubMed]

42. Trufelli, H.; Palma, P.; Famiglini, G.; Cappiello, A. An overview of matrix effects in liquid chromatography-mass spectrometry. Mass Spectrom. Rev. 2011, 30, 491-509. [CrossRef] [PubMed]

43. Robinson, N.A.; Pace, J.G.; Matson, C.F.; Miura, G.A.; Lawrence, W.B. Tissue distribution, excretion and hepatic biotransformation of microcystin-LR in mice. J. Pharmacol. Exp. Ther. 1991, 256, 176-182.

44. Cheng, X.; Maher, J.M.; Lu, H.; Klaassen, C.D. Endocrine regulation of gender-divergent mouse organic anion transporting polypeptide (Oatp) expression. Mol. Pharmacol. 2006, 70, 1291-1297. [CrossRef]

45. Chen, J.; Xie, P.; Li, L.; Xu, J. First identification of the hepatotoxic microcystins in the serum of a chronically exposed human population together with indication of hepatocellular damage. Toxicol. Sci. 2009, 108, 81-89. [CrossRef]

46. Zheng, C.; Zeng, H.; Lin, H.; Wang, J.; Feng, X.; Qiu, Z.; Chen, J.A.; Luo, J.; Luo, Y.; Huang, Y.; et al. Serum microcystin levels positively linked with risk of hepatocellular carcinoma: A case-control study in southwest China. Hepatology 2017, 66, 1519-1528. [CrossRef]

47. Pflugmacher, S.; Wiegand, C.; Oberemm, A.; Beattie, K.A.; Krause, E.; Codd, G.A.; Steinberg, C.E.W. Identification of an enzymatically formed glutathione conjugate of the cyanobacterial hepatotoxin microcystin-LR: The first step of detoxication. Biochim. Biophys. Acta 1998, 1425, 527-533. [CrossRef]

48. Wang, Q.; Xie, P.; Chen, J.; Liang, G. Distribution of microcystins in various organs (heart, liver, intestine, gonad, brain, kidney and lung) of Wistar rat via intravenous injection. Toxicon 2008, 52, 721-727. [CrossRef] [PubMed]

49. Li, W.; He, J.; Chen, J.; Xie, P. Excretion pattern and dynamics of glutathione detoxification of microcystins in Sprague Dawley rat. Chemosphere 2018, 191, 357-364. [CrossRef] [PubMed]

50. Greer, B.; Meneely, J.P.; Elliott, C.T. Uptake and accumulation of Microcystin-LR based on exposure through drinking water: An animal model assessing the human health risk. Sci. Rep. 2018, 8, 4913. [CrossRef] [PubMed]

51. Fu, Q.; Chen, M.; Anderson, J.T.; Sun, X.; Hu, S.; Sparreboom, A.; Baker, S.D. Interaction Between Sex and Organic Anion-Transporting Polypeptide 1b2 on the Pharmacokinetics of Regorafenib and Its Metabolites Regorafenib-N-Oxide and Regorafenib-Glucuronide in Mice. Clin. Transl. Sci. 2019. [CrossRef] [PubMed]

52. Zemskov, I.; Altaner, S.; Dietrich, D.R.; Wittmann, V. Total Synthesis of Microcystin-LF and Derivatives Thereof. J. Org. Chem. 2017, 82, 3680-3691. [CrossRef] [PubMed]

(C) 2019 by the authors. Licensee MDPI, Basel, Switzerland. This article is an open access article distributed under the terms and conditions of the Creative Commons Attribution (CC BY) license (http://creativecommons.org/licenses/by/4.0/). 